Article

\title{
Dispersion of Carbon Nanotubes with Different Types of Superplasticizer as a Dispersing Agent for Self-Sensing Cementitious Materials
}

\author{
Pedro de Almeida Carísio ${ }^{1, *} \mathbb{0}$, Yasmim Gabriela dos Santos Mendonça ${ }^{1}$, Carlos Fernando Teodósio Soares ${ }^{2}$, \\ Oscar Aurelio Mendoza Reales ${ }^{1}$, Eduardo de Moraes Rego Fairbairn ${ }^{1}{ }^{\mathbb{D}}$ and Romildo Dias Toledo Filho ${ }^{1} \mathbb{E}$ \\ 1 Civil Engineering Program-COPPE, Federal University of Rio de Janeiro, Rio de Janeiro 21941-594, Brazil; \\ yasmim@numats.coc.ufrj.br (Y.G.d.S.M.); oscar@coc.ufrj.br (O.A.M.R.); eduardo@coc.ufrj.br (E.d.M.R.F.); \\ toledo@coc.ufrj.br (R.D.T.F.) \\ 2 Elecronics and Computer Engineering Department-POLI, Federal University of Rio de Janeiro, \\ Rio de Janeiro 21941-594, Brazil; teodosio@poli.ufrj.br \\ * Correspondence: pedro.carisio@numats.coc.ufrj.br
}

Citation: de Almeida Carísio, P.; dos Santos Mendonça, Y.G.; Soares, C.F.T.; Reales, O.A.M.; de Moraes Rego Fairbairn, E.; Filho, R.D.T. Dispersion of Carbon Nanotubes with Different Types of Superplasticizer as a Dispersing Agent for Self-Sensing Cementitious Materials. Appl. Sci. 2021, 11, 8452. https://doi.org/ 10.3390/app11188452

Academic Editor:

Antonella D'Alessandro

Received: 19 August 2021

Accepted: 10 September 2021

Published: 12 September 2021

Publisher's Note: MDPI stays neutral with regard to jurisdictional claims in published maps and institutional affiliations.

Copyright: (c) 2021 by the authors. Licensee MDPI, Basel, Switzerland. This article is an open access article distributed under the terms and conditions of the Creative Commons Attribution (CC BY) license (https:/ / creativecommons.org/licenses/by/ $4.0 /)$.
Featured Application: Cement paste blended with carbon nanotubes for self-sensing applications.

Abstract: Due to their exceptional electrical properties, carbon nanotubes (CNTs) can be applied as conductive fillers to develop self-sensing cement-based matrices. In order to obtain an adequate self-sensing response, CNTs must be evenly dispersed through the cement matrix in a volume sufficient enough to create an electric percolation network. This is challenged by the difficulty of dispersing CNTs; therefore, there is a demand for an efficient dispersing agent that can be filled by superplasticiezers, which are products of known compatibility with cement and high availability. This research explores the use of four commercial superplasticizers available in Brazil, both naphthalene and ether polycarboxylate-based, as dispersing agents for CNTs in water. Ultrasonic energy was applied to aqueous solutions containing CNTs and superplasticizers. UV-Vis spectroscopy and $\xi$-potential measurements were used to investigate which superplasticizer was more effective to disperse the CNTs. Cement pastes were produced with the CNT dispersions and their electrical resistivity was measured. It was found that only superplasticizers without aliphatic groups in their structure were capable of dispersing CNTs in water. It was concluded that second-generation naphthalene-based superplasticizers were more efficient dispersing agents for CNTs than thirdgeneration ether polycarboxylate-based ones for self-sensing applications.

Keywords: carbon nanotubes; dispersion; superplasticizer; resistivity

\section{Introduction}

Due to their high tensile strength of up to $60 \mathrm{GPa}$ [1], carbon nanotubes (CNTs) are considered a superior material for nano-reinforcement of cement-based composites [2]. CNTs have been found to increase the mechanical strength of pastes, mortars, and concretes [3-6] through four different mechanisms: crack bridging, matrix densification, pore filling, and C-S-H nucleation [7]. Additionally, due to their electric and magnetic properties [8], CNTs have the potential for developing novel construction materials with smart properties, such as self-sensing, self-heating, electromagnetic shielding [9], and self-healing [10].

Many authors have reported a decrease in mechanical properties of cement-based composites due to the presence of poorly dispersed CNTs in the cement matrix $[5,11]$. Due to their hydrophobic nature and Van der Waals interactions [12,13], CNTs tend to agglomerate, forming bundles that induce weakness regions in the composites [2]. It is now known that appropriate reinforcement does not only depend on the intrinsic properties of CNTs, but also on how well they are dispersed throughout cement matrices [14]. Selfsensing applications, based on CNTs as a conductive filler, also rely on proper nanotube 
dispersion to form a continuous electrically conductive path, i.e., reaching the electrical percolation threshold [9].

There are three main strategies to disperse CNTs: physical methods, chemical methods, and a combination of both. Some of the physical methods usually employed are sonication, mechanical stirring, and ball milling. It has been found that ball milling and mechanical stirring are not efficient enough [7], while controlled ultrasonic pulses have been found to be an efficient method for dispersing CNTs through induced cavitation [15-17]. Chemical methods employ dispersing agents that improve CNT wettability and induce electrostatic repulsion between individual tubes. Some of the most commonly used chemical dispersing agents for CNTs are surfactants [2,18-20] and superplasticizers (SP) [21,22]. Surfactants have been found to directly affect the cement matrix [23], delaying the hydration reaction and increasing the amount of entrapped air. Superplasticizers are considered a more promising dispersing agent due to their compatibility with cement; nevertheless, effective dispersion of CNTs without affecting the properties of the cement matrix still is a challenge.

Superplasticizers can be seen as effective in performing dual function, dispersing both cement grains and CNTs. By means of electrostatic repulsion, SPs act at the cement grain surface, inducing repulsion between grains. At the same time, due to their structure, which combines hydrophobic and hydrophilic groups, SPs may adsorb on the surface of CNTs, increasing their wettability and maintaining individual nanotubes separated [24]. Due to this dual function, SPs have a potential to be used as a CNT dispersant agent in cement composites.

UV-Vis spectroscopy and $\zeta$-potential have been found to be good techniques in characterizing CNT dispersions in water [25]. Individual CNTs can be identified through their characteristic absorption band around $253 \mathrm{~nm}$ [26], while $\zeta$-potential identifies the magnitude of colloidal particles electrostatic interaction and characterizes the stability of CNT-water colloidal systems [27]. This work uses results obtained from both techniques as a basis for optimizing a CNT ultrasonic dispersion process with four different commercially available SP, of two different chemical bases, as dispersing agents. UV-Vis absorbance and $\zeta$-potential values were used to characterize the efficiency of each SP in water, while the structural integrity of CNTs after sonication was verified using Raman Spectroscopy. Electrical resistivity was used to characterize the efficiency of each SP after CNTs were blended into the cement-based composites.

\section{Materials and Methods}

\subsection{Materials and Materials Characterization}

The materials used were multiwalled carbon nanotubes (CNTs) NC7000 in powder produced by Nanocyl (Nanocyl S.A., Sambreville, Belgium); early strength development Portland cement (Lafarge-Holcim, Rio de Janeiro, Brazil); viscosity modifying agent (VMA) (BASF, São Paulo, Brazil); and four types of superplasticizers (SPs) as dispersing agents for CNTs. The SPs included Glenium 51 (BASF, São Paulo, Brazil), ADI-SUPER H40 (Aditibrás, Dique de Caxias, Brazil), MC-PowerFlow 1180 (MC-Bauchemie, Vargem Grande Paulista, Brazil), and Hormitec SP430 (Anchortec, Mogi das Cruzes, Brazil) - the first three were polycarboxylate-based and the latter was naphthalene-based. Each SP received a code from A to D, as presented in Table 1. Fourier transform infrared spectroscopy (FTIR) was used to investigate the structural differences between the four SP. A FTIR Thermo Scientific Nicolet 6700 spectrometer was used in transmission mode with KBr pellets. CNTs were characterized through Raman spectroscopy in a Horiba Jobin Yvon HR800 UV, using an objective lens of 100X magnification and a 514-nm laser, and, through transmission electron microscopy (TEM), a STEM microscope from FEI, in a bright field transmission mode set to $75 \mathrm{kV}$ acceleration and in a copper \#300 Formvar mesh. 
Table 1. Nomenclature used for superplasticizers and their solid content. ( ${ }^{*}$ Informed by the manufacturer).

\begin{tabular}{cccc}
\hline Code & Superplasticizer Name & Solids Content * & Superplasticizer Type \\
\hline A & Glenium 51 & $33 \%$ & Ether polycarboxylate \\
B & ADI-SUPER H40 & $40 \%$ & Ether polycarboxylate \\
C & MC-PowerFlow 1180 & $35 \%$ & Ether polycarboxylate \\
D & Hormitec SP430 & $40 \%$ & Naphtalene \\
\hline
\end{tabular}

\subsection{CNT Dispersion in Water Using SPs and Ultrassound}

$\mathrm{CNT} / \mathrm{SP} /$ water dispersions were produced using $0.25 \%$ wt. of CNT and each type of SP (1:4 ratio of CNT to SP), as presented in Table 2. Dispersions were placed in an ice bath and sonicated with a 550-W ultrasonic tip processor using $40 \%$ amplitude in 20 -s on/off cycles to avoid overheating the samples. An aliquot from each dispersion was taken every $100 \mathrm{~J} / \mathrm{g}_{\text {dispersion }}$ and analyzed in a spectrophotometer (Flame UV-Vis Miniature Spectrometer-Ocean Optics) to measure its absorbance spectra in the UV-Vis range. Dispersion degree was determined through the absorbance value at a $250-\mathrm{nm}$ wavelength. Sonication cycles were repeated until the absorbance value at $250 \mathrm{~nm}$ did not present a variation of more than 0.1 (arbitrary units) for three repeated cycles.

Table 2. CNT:SP proportions and total sonication energy for each CNT dispersion.

\begin{tabular}{ccccccc}
\hline Dispersion & SP Type & CNT (\%) & SP (\%) & Water (\%) & CNT:SP & $\begin{array}{c}\text { Sonication Energy } \\
\left(\mathbf{J} / \mathbf{g}_{\text {dispersion }}\right)\end{array}$ \\
\hline $0.25 \% \mathrm{CNT} / 1.00 \%$ SP A & $\mathrm{A}$ & & & & & 900 \\
$0.25 \% \mathrm{CNT} / 1.00 \%$ SP B & $\mathrm{B}$ & 0.25 & 1.00 & 98.75 & $1: 4$ & 1000 \\
$0.25 \% \mathrm{CNT} / 1.00 \%$ SP C & $\mathrm{C}$ & & & & & 1000 \\
$0.25 \% \mathrm{CNT} / 1.00 \% \mathrm{SP}$ D & $\mathrm{D}$ & & & & 1000 \\
\hline
\end{tabular}

After identification of the maximum absorbance value, samples were dropped on glass microscopy slides and dried in a desiccator to verify the structural integrity of the MWCT using Raman spectroscopy. Stability of the obtained dispersions was characterized through $\zeta$-potential experiments using a Malvern Zetasizer Nano Instrument equipped with an electrophoretic light scattering cell.

\subsection{CNT-Cement Composites Preparation and Electrical Characterization}

Cement pastes were produced using early strength development cement with a fixed water/cement $(w / c)$ ratio of 0.50 and $0.60 \%$ of VMA by mass of cement to prevent water exudation. Samples were prepared by hand mixing the obtained dispersions with cement and VMA, which resulted in cement-based composites containing 0.10 and $0.40 \%$ CNT by mass of cement, as presented in Table 3. Cylinders (10 mm diameter and $20 \mathrm{~mm}$ height) were casted and cured at high relative humidity for 14 days. A total of 5 specimens were molded for each condition. After curing, all samples were dried in an oven at $40^{\circ} \mathrm{C}$ for $24 \mathrm{~h}$.

Table 3. CNT-cement composites proportions adopted for electrical resistivity measurements. (* percentage by mass of cement).

\begin{tabular}{ccccc}
\hline Composite & CNT $\left(\%{ }^{*}\right)$ & Cement (\%) & VMA (\% *) & $w / c$ \\
\hline REF & - & & & \\
\cline { 1 - 2 } $0.10 \%$ CNT-cement/SP A & & & & \\
$0.10 \%$ CNT-cement/SP B & 0.10 & & 0.60 & \\
$0.10 \%$ CNT-cement/SP C & & & \\
$0.10 \%$ CNT-cement/SP D & & & \\
0.40\% CNT-cement/SP A & & & \\
$0.40 \%$ CNT-cement/SP B & 0.40 & & \\
$0.40 \%$ CNT-cement/SP C & & & \\
$0.40 \%$ CNT-cement/SP D & & & \\
\hline
\end{tabular}


Copper sheets of a $0.1 \mathrm{~mm}$ thickness were glued to the end of the cylinders with silver conductive glue. A constant voltage of 5.0 V DC was applied to each sample for 20 min before measurement for signal stabilization [28]. The current (I) passing through the sample was measured using a $6 \frac{1}{2}$ digits resolution Keysight model 34461A multimeter. The applied voltage (V) was verified using a hand-held multimeter Hikari model HM-20230. Since the hand-held multimeter has an internal resistance of the same order of magnitude observed in the samples under test, the measurement setup, shown in Figure 1a, was adopted to mitigate its influence on the results. The electrical resistance of each sample was computed using Ohm's law, according to Equation (1), and the electrical resistivity $(\rho)$ of the material was obtained using the cross section area (A) and length (l) of the samples, according to Equation (2). An example of the cement paste specimens is presented in Figure $1 b$.

$$
\begin{gathered}
\mathrm{R}(\Omega)=\mathrm{V}(\mathrm{V}) / \mathrm{I}(\mathrm{A}) \\
\rho(\Omega . \mathrm{cm})=\mathrm{R}(\Omega) \cdot \mathrm{A}\left(\mathrm{cm}^{2}\right) / 1(\mathrm{~cm})
\end{gathered}
$$
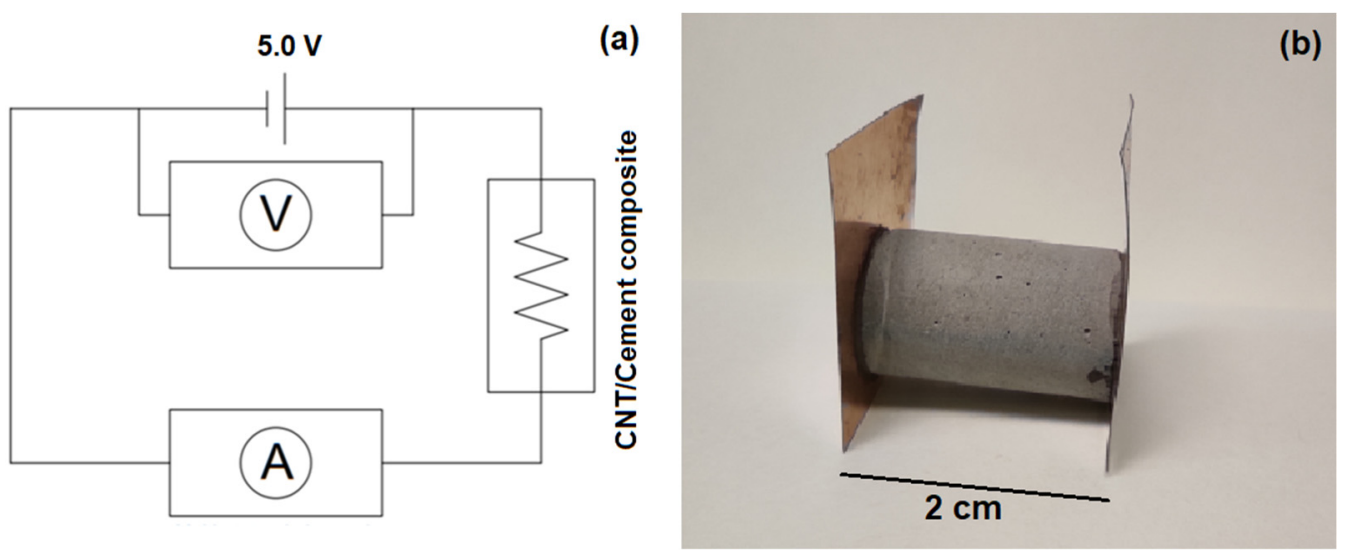

Figure 1. (a) Electrical circuit adopted for the electrical resistivity measurements and (b) cement paste specimen.

\section{Results}

\subsection{Materials Characterization}

FTIR spectra obtained for the four SPs used are presented in Figure 2. JanowskaRenkas [29] cite that specific functional groups from superplasticizers can be verified through their absorption bands in FTIR spectra as OH- groups $\left(3600-3200 \mathrm{~cm}^{-1}\right)$; aliphatic groups (3200-2500 $\mathrm{cm}^{-1}$ ); carbonyl groups (1900-1500 $\left.\mathrm{cm}^{-1}\right)$; and ether groups (1250-950 $\mathrm{cm}^{-1}$ ). It can be observed that the chosen SP presented absorption bands in the regions cited, with some differences among them.

FTIR spectra from SP A and C are analogous, differing only in one absorption band at $1560 \mathrm{~cm}^{-1}$ (carbonyl groups). It should be noticed that the absorption bands present at $2920 \mathrm{~cm}^{-1}$ (aliphatic groups) for SP A and C did not appear in SP B and D. Superplasticizer D presented the most differences among all SPs, such as not showing any band at $950 \mathrm{~cm}^{-1}$ (ether groups), and two additional bands at 1035 and $1190 \mathrm{~cm}^{-1}$. This difference is associated with its naphthalene basis.

Raman spectrum and TEM imaging of CNTs prior to sonication are presented in Figure 3. Two peaks can be identified in the Raman spectrum, one at $1344 \mathrm{~cm}^{-1}$, attributed to amorphous carbon structures and some defects (namely D band), and one at $1579 \mathrm{~cm}^{-1}$, attributed to tangential C-C bond stretching vibrations (namely $\mathrm{G}$ band) $[22,30]$. CNTs were found to have a $\mathrm{I}_{\mathrm{D}} / \mathrm{I}_{\mathrm{G}}$ of 1.29 , characteristic of highly graphitized structures. TEM imaging confirmed that the CNTs presented an outer diameter in the scale of nanometers and length in the scale of micrometers. Additional images of the used CNTs can be found in $[31,32]$. 


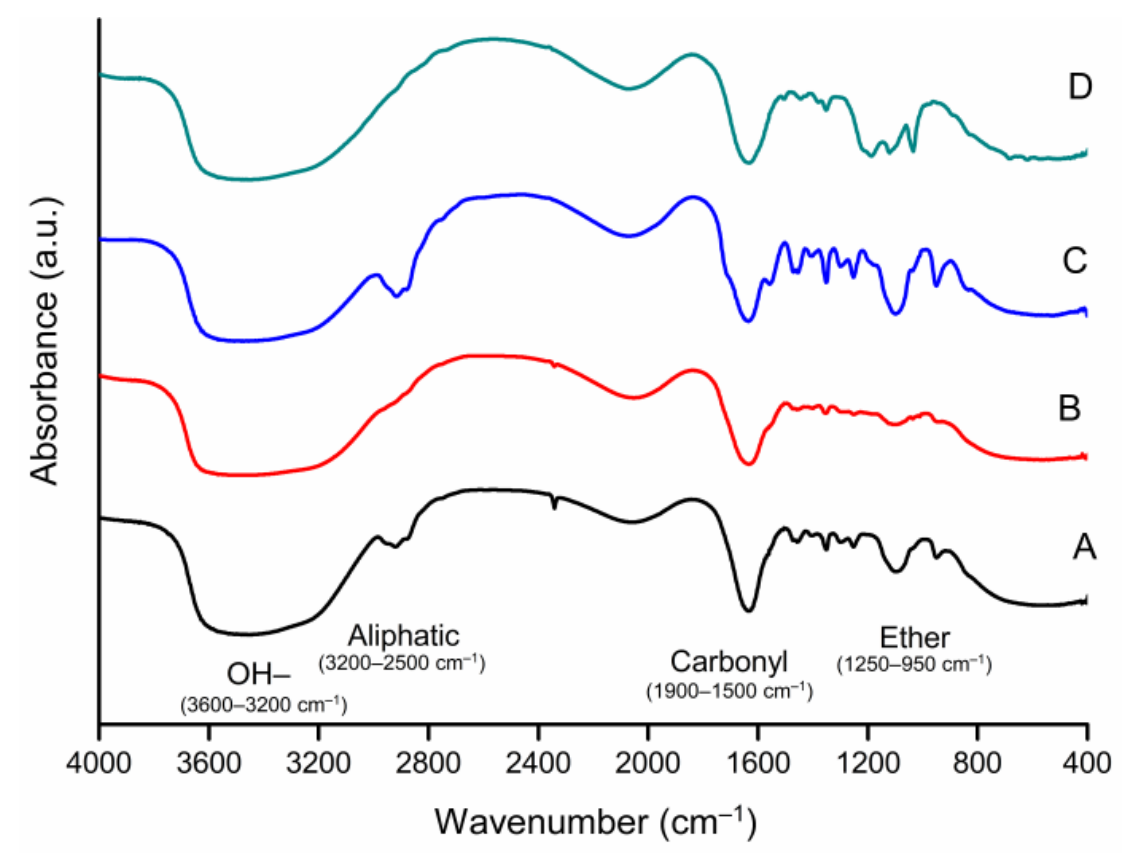

Figure 2. FTIR spectra of superplasticizers A, B, C and D.
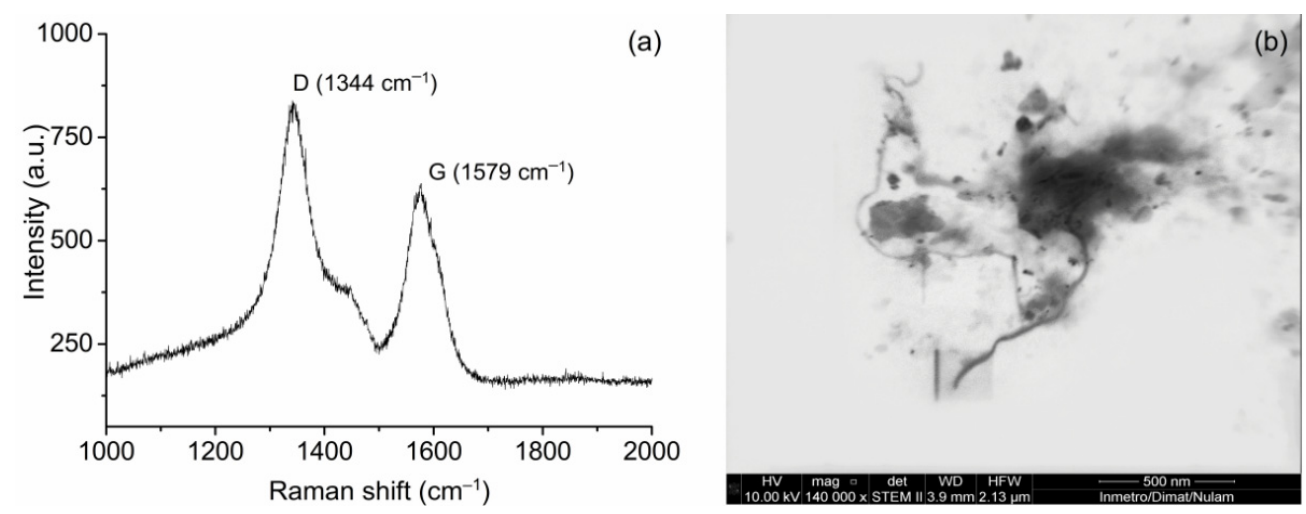

Figure 3. (a) RAMAN spectrum and (b) transmission electron microscopy of pristine CNTs.

\subsection{CNT Dispersion in Water Using SP and Ultrassound}

The obtained absorbance spectra and $\zeta$-potential results for the CNT/water/SP dispersions are presented in Figure 4. Absorbance spectra showed that all samples exhibit a characteristic peak around $250 \mathrm{~nm}$, corresponding to the presence of individual CNTs. SPs $\mathrm{A}, \mathrm{B}$, and $\mathrm{C}$ showed smooth absorbance profiles with one pronounced peak corresponding to individual CNTs. SP D showed two pronounced peaks, one corresponding to CNTs and one corresponding to the SP naphthalene aromatic groups. ל-potential results showed that all SPs conferred a negative surface charge to the CNT. It is known that the higher the absolute value of $\zeta$-potential, the more stable a colloid would be [33], and that for cement-based systems absolute values above $25.0 \mathrm{mV}$ yield stable suspensions [34]. It was found that only SP D presented a result above $25.0 \mathrm{mV}$ in absolute value. 

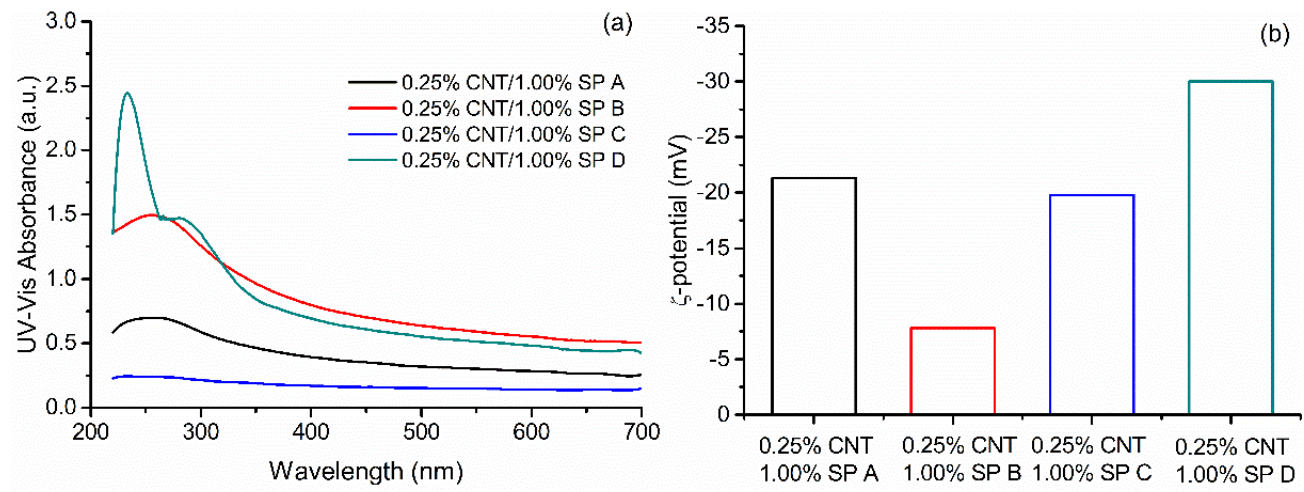

Figure 4. (a) UV-Vis absorbance spectra and (b) $\zeta$-potential values of different $\mathrm{CNT} / \mathrm{SP} /$ water dispersions with $0.25 \%$ of CNT and $1.00 \%$ of all studied SP.

Raman spectra were used to verify any damage induced on the CNTs by the sonication process for all SPs studied. The obtained $\mathrm{I}_{\mathrm{G}} / \mathrm{I}_{\mathrm{D}}$ values, which describe the density of structural defects, are presented in Figure 5. All dispersions presented $I_{G} / I_{D}$ values lower than the pristine CNTs, indicating sonication-induced damage in all samples, regardless of the SP type or CNT:SP ratio used. No clear trend could be identified regarding the type of $\mathrm{SP}$ and the amount of damage induced on the CNTs.

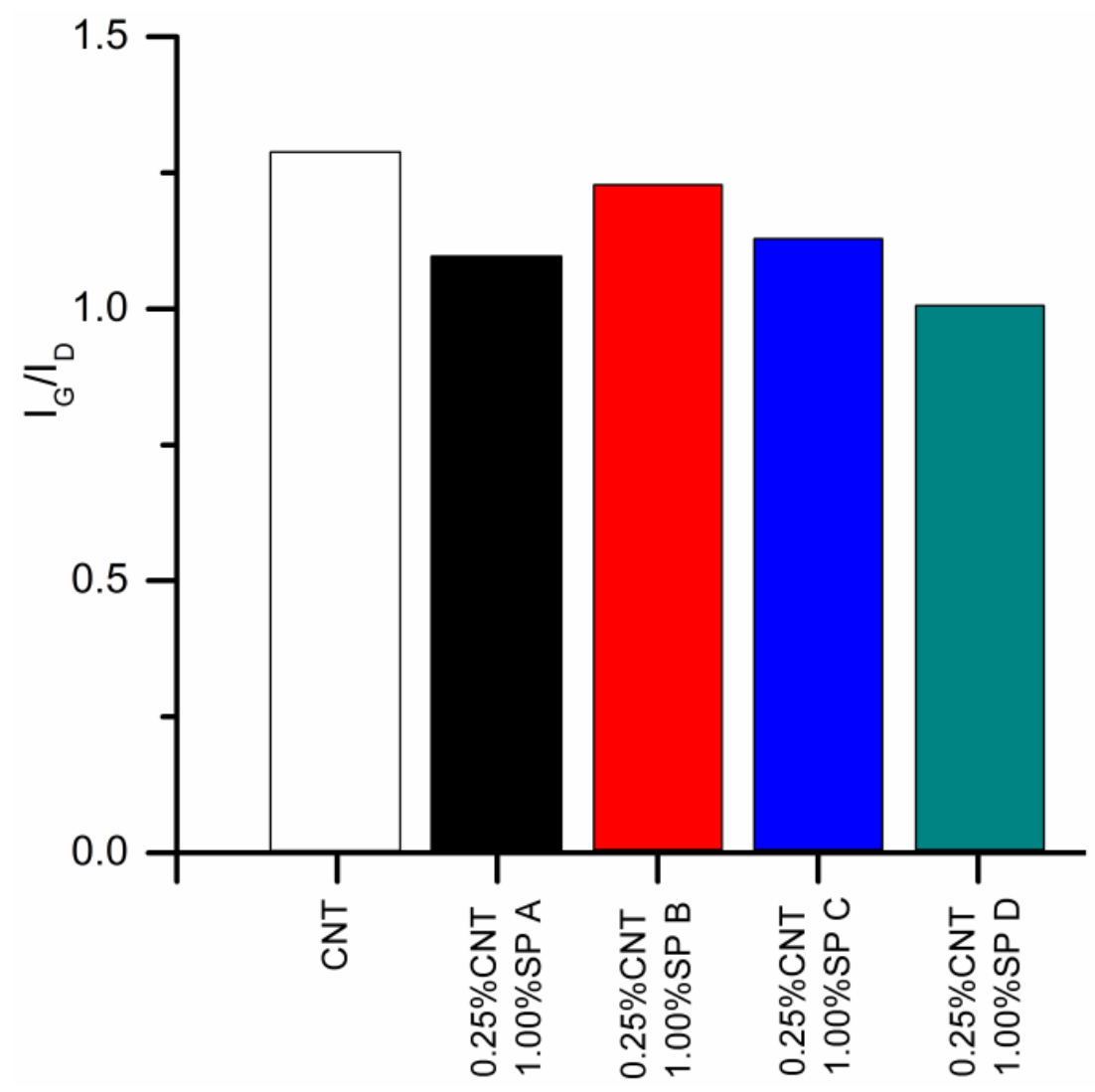

Figure 5. $\mathrm{I}_{\mathrm{G}} / \mathrm{I}_{\mathrm{D}}$ ratios obtained from Raman spectroscopy results for all $\mathrm{CNT}$ dispersions studied.

After initial screening of the four SPs, clear differences in dispersing efficiency could be identified among them. To better understand the limitations of each type of SP, variations in CNT:SP concentrations were performed. Using the UV-Vis results, SPs were divided in two groups, $\mathrm{B}$ and $\mathrm{D}$, as the best performing, and $\mathrm{A}$ and $\mathrm{C}$, as the worse performing. The obtained results are presented in the following sections. 


\subsubsection{CNT:SP Variations for SPs B and D}

In order to obtain a more concentrated CNT dispersions using SPs B and D, CNT concentrations were increased to 0.40 and $0.80 \%$, while CNT-SP ratios were increased to 1:4 and 1:2, respectively. The new adopted proportions are presented in Table 4 and the obtained absorbance spectra and $\zeta$-potential results are presented in Figure 6. Results for SP D showed a similar behavior to the one found for the $0.25 \% \mathrm{CNT} / 1.00 \%$ SP dispersions, indicating that increasing CNT concentration and decreasing the SP amount did not compromise the dispersion efficiency of SP D. On the other hand, results for SP B showed that a higher CNT concentration compromised its dispersing efficiency.

Table 4. CNT-SP proportions and total sonication energy for SP B and D refinements.

\begin{tabular}{ccccccc}
\hline Dispersion & SP Type & CNT (\%) & SP (\%) & Water (\%) & CNT:SP & $\begin{array}{c}\text { Sonication Energy } \\
\left(\mathbf{J} / \mathbf{g}_{\text {dispersion }}\right)\end{array}$ \\
\hline $0.40 \% \mathrm{CNT} / 1.60 \%$ SP B & $\mathrm{B}$ & 0.40 & 1.60 & 98.00 & $1: 4$ & 1100 \\
$0.80 \% \mathrm{CNT} / 1.60 \%$ SP B & $\mathrm{B}$ & 0.80 & 1.60 & 97.60 & $1: 2$ & 1000 \\
$0.40 \% \mathrm{CNT} / 1.60 \%$ SP D & $\mathrm{D}$ & 0.40 & 1.60 & 98.00 & $1: 4$ & 900 \\
$0.80 \% \mathrm{CNT} / 1.60 \%$ SP D & $\mathrm{D}$ & 0.80 & 1.60 & 97.60 & $1: 2$ & 1000 \\
\hline
\end{tabular}
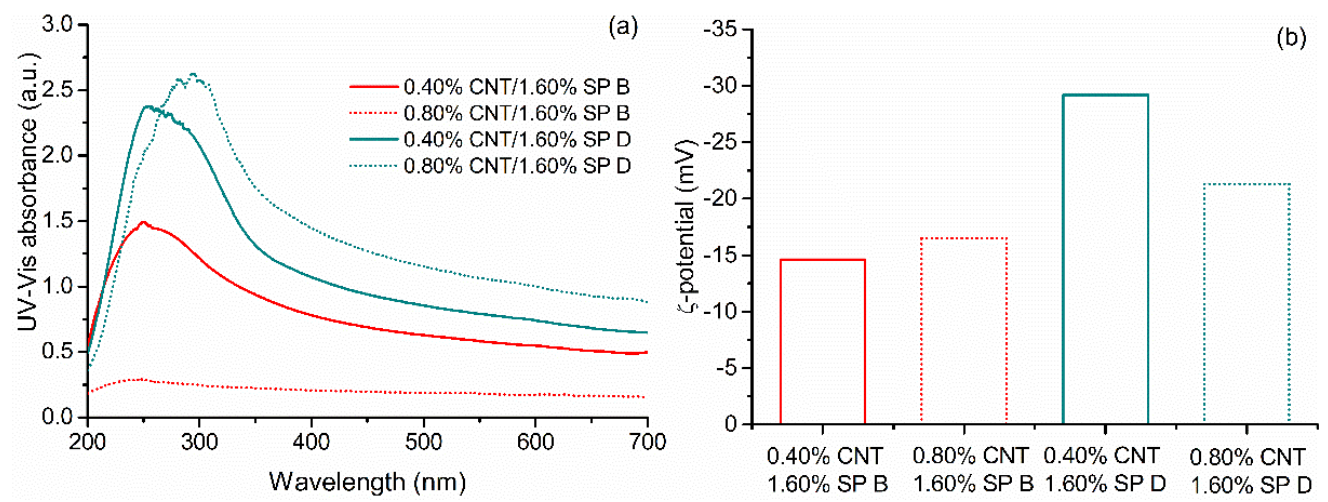

Figure 6. (a) UV-Vis absorbance spectra and (b) ל-potential values obtained from different CNT:SP variations using SPs B and D.

\subsubsection{CNT-SP Variations for SPs A and C}

Since absorbance results indicated that SPs A and C were the worst performing dispersing agents, both the CNT concentration and SP:CNT ratios were varied. The new adopted proportions are presented in Table 5 and the obtained absorbance spectra and $\zeta$ potential results are presented in Figure 7. Results showed that none of the tested variations resulted in a significant increase in the absorbance value at $250 \mathrm{~nm}$, indicating that CNT could not be properly dispersed by SPs A and C.
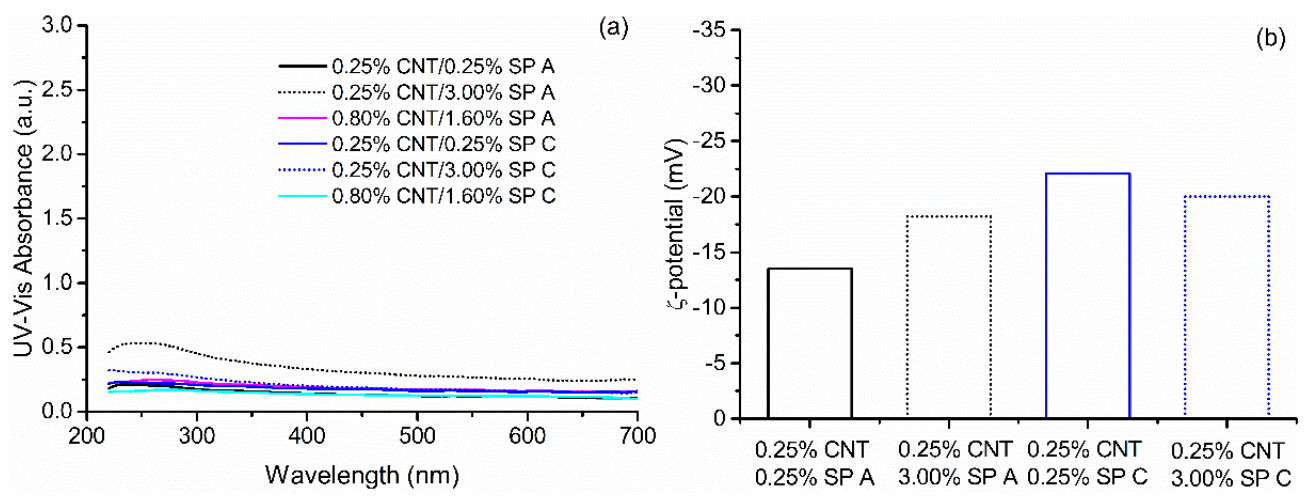

Figure 7. (a) UV-Vis absorbance spectra and (b) $\zeta$-potential values obtained from different CNT-SP variations using SPs $\mathrm{A}$ and $\mathrm{C}$. 
Table 5. CNT-SP proportions and total sonication energy for SP A and C refinements.

\begin{tabular}{|c|c|c|c|c|c|c|}
\hline Dispersion & SP Type & CNT (\%) & SP (\%) & Water (\%) & CNT:SP & $\begin{array}{c}\text { Sonication Energy } \\
\left(\mathrm{J} / \mathrm{g}_{\text {dispersion }}\right)\end{array}$ \\
\hline $0.25 \% \mathrm{CNT} / 0.25 \% \mathrm{SP}$ A & A & 0.25 & 0.25 & 99.50 & $1: 1$ & 600 \\
\hline $0.25 \% \mathrm{CNT} / 3.00 \% \mathrm{SP}$ A & A & 0.25 & 3.00 & 96.75 & 1:12 & 900 \\
\hline $0.80 \% \mathrm{CNT} / 1.60 \% \mathrm{SP}$ A & A & 0.80 & 1.60 & 97.60 & $1: 2$ & 1000 \\
\hline $0.25 \% \mathrm{CNT} / 0.25 \%$ SP C & C & 0.25 & 0.25 & 99.50 & $1: 1$ & 600 \\
\hline $0.25 \% \mathrm{CNT} / 3.00 \% \mathrm{SPC}$ & $\mathrm{C}$ & 0.25 & 3.00 & 96.75 & $1: 12$ & 800 \\
\hline $0.80 \% \mathrm{CNT} / 1.60 \% \mathrm{SP} C$ & $\mathrm{C}$ & 0.80 & 1.60 & 97.60 & $1: 2$ & 1000 \\
\hline
\end{tabular}

\subsection{Electrical Resistivity of the CNT-Cement Composites}

Electrical resistivity measurements were performed for the cement-based composites containing $0.00 \%, 0.10 \%$, and $0.40 \%$ CNT by mass of cement and the four SPs studied. Five specimens were tested for each condition. The CNT amounts by mass of cement were chosen as the maximum achievable using the CNT concentration in the aqueous dispersions for the selected a/c. The $0.10 \%$ CNT-cement composites were produced with the $0.25 \%$ CNT and $1.00 \%$ SP dispersions, while the $0.40 \%$ CNT-cement composites were produced with the $0.80 \% \mathrm{CNT}$ and $1.60 \%$ SP dispersions. All SPs were tested in order to verify if the best dispersion conditions identified through UV-Vis spectroscopy were translated into lower electrical resistance values.

Typical obtained resistivity versus time results are presented in Figure 8. A transient behavior, also called the drift effect [35], was identified in all samples and associated with polarization phenomena due to the dielectric nature of the cement matrix [36]. This effect has been found to appear when performing measurements with a DC power source [37]. Nevertheless, allowing a given amount of time for measurement stabilization has been reported as a satisfactory solution [28]. After $20 \mathrm{~min}$ of constant voltage application, two different types of behaviors could be identified: one corresponding to a fast stabilization of the resistivity measurement, and one corresponding to a slow stabilization.

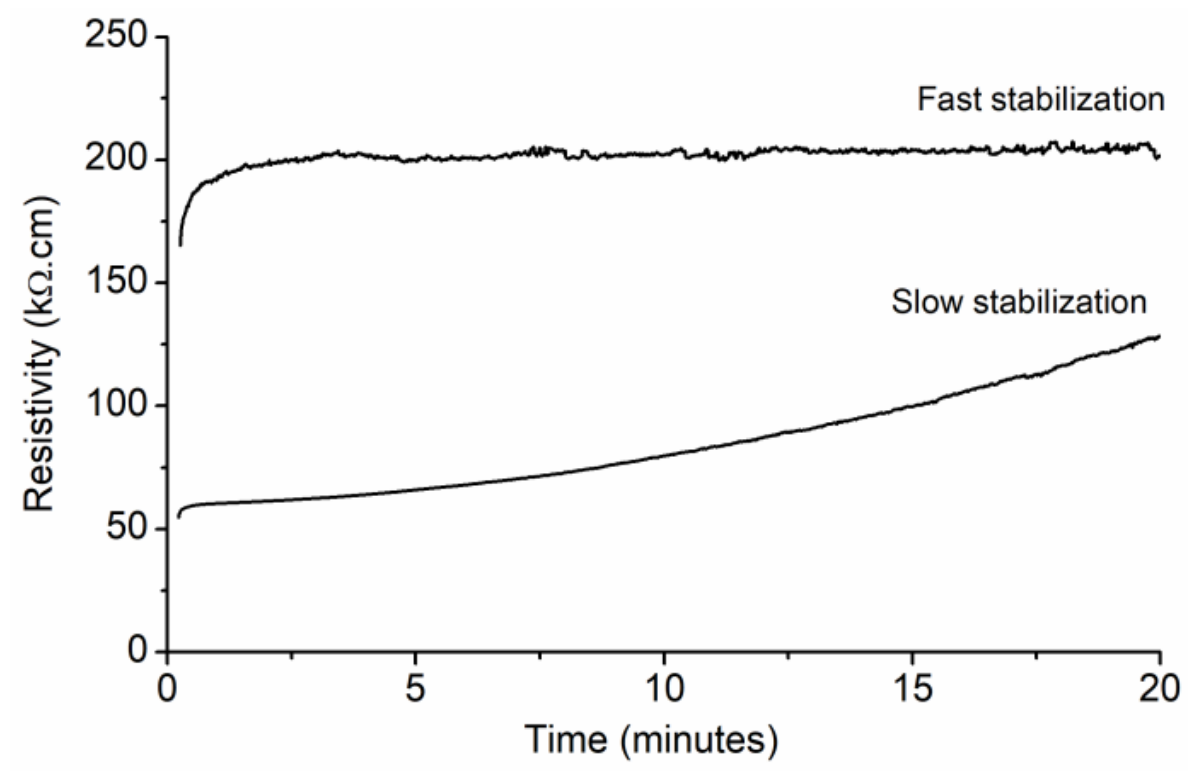

Figure 8. Typical electrical resistivity results over time obtained for CNT-cement composites.

The stabilization time between 4 and 20 min of constant voltage application, presented as a fraction of their initial resistance $\left(\mathrm{R} / \mathrm{R}_{0}\right)$ [35] for $0.40 \%$ CNT-cement composites, is shown in Figure 9. The $R / R_{0}$ values were obtained starting from the fourth minute of testing in order to discard the initial sharp curvature and analyze the more linear part of the result. It was found that the electrical resistance of the samples produced with SPs $A$ and $C$, which presented lower dispersing efficiency, also presented slow stabilization 
behavior. On the other hand, the electrical resistance of samples produced with SPs B and $D$, which presented higher dispersing efficiency, could be considered stable after very short stabilization periods. This indicates that faster stabilization times are associated with better $\mathrm{CNT}$ dispersion in the cement matrix.
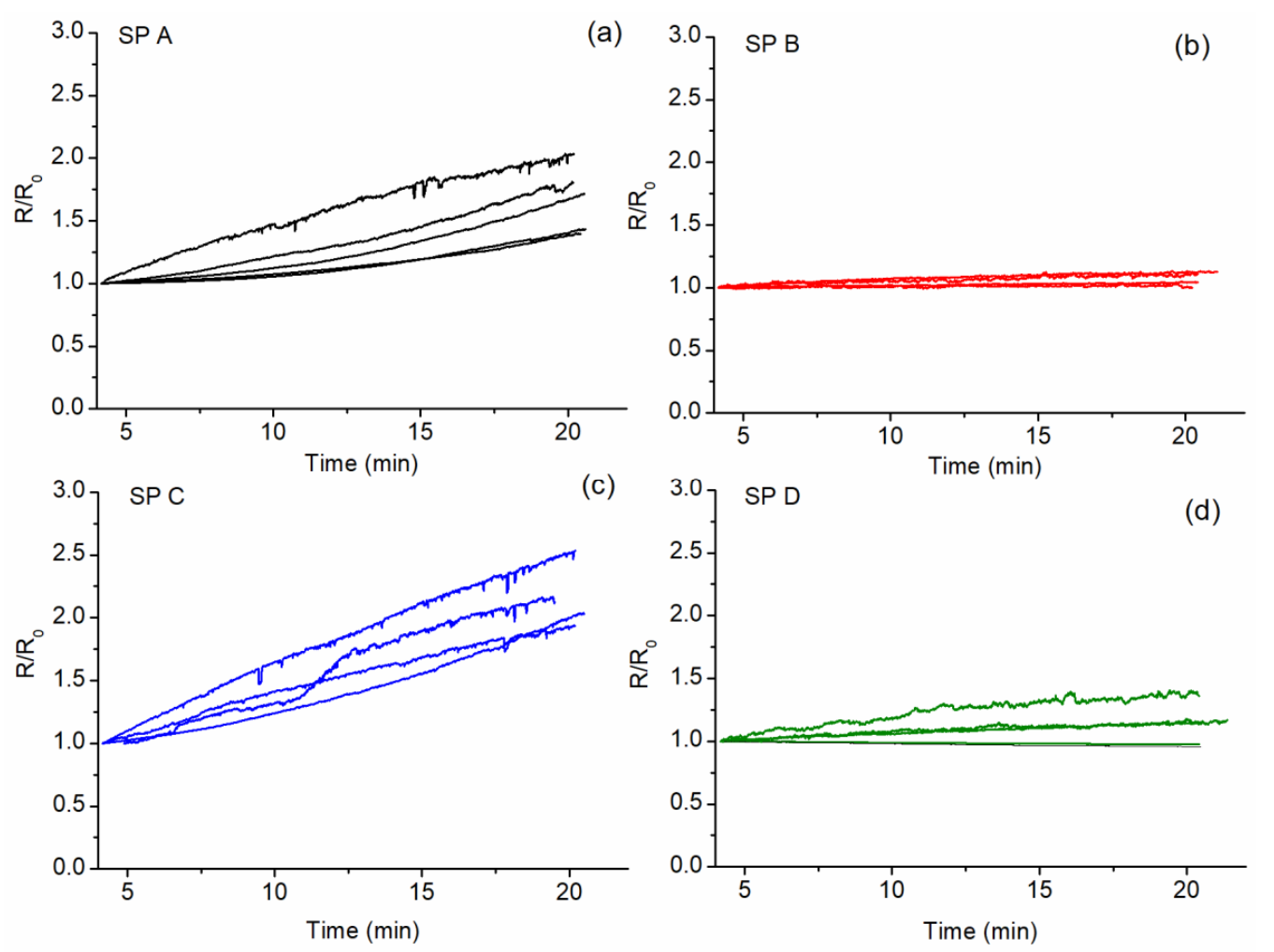

Figure 9. Electrical resistance evolution over time between 4 and $20 \mathrm{~min}$ of constant voltage application, presented as a fraction of the initial resistance $\left(\mathrm{R} / \mathrm{R}_{0}\right)$ for $0.40 \% \mathrm{CNT}$-cement composites. (a) $\mathrm{SP}$ A, (b) SP B, (c) SP C and (d) SP D.

Electrical resistivity results of all cement-based composites after $20 \mathrm{~min}$ of constant voltage application are presented in Figure 10. It was found that all the cement-CNT composites had a lower electrical resistivity than the reference cement sample, and that this resistivity decreased proportionally to the amount of CNT present in the matrix. At the highest CNT dosage ( $0.40 \%$ by mass of cement), it was found that the samples produced with superplasticizers A and D presented an average resistivity of $150 \mathrm{k} \Omega . \mathrm{cm}$, while the samples produced with superplasticizers $B$ and D presented and average resistivity of $50.0 \mathrm{k} \Omega . \mathrm{cm}$, a 130 times decrease when compared to the resistivity of the reference sample $(6.5 \mathrm{M} \Omega . \mathrm{cm})$. This confirms the trend identified in the UV-Vis results, where SP $\mathrm{B}$ and D were found to be more efficient dispersing agents than SPs A and C. Special attention should be given to the resistivity results obtained for the $0.40 \%$ CNT-cement-SPB composites. These samples were prepared with the $0.80 \% \mathrm{CNT}$ and $1.60 \% \mathrm{CNT}$ dispersion, which did not present satisfactory UV-Vis results. Their low obtained resistivity can be associated with conduction through CNT agglomerates rather than through individual nanotubes $[38,39]$ and may be the cause of the higher dispersion of the results. This phenomena has also been reported for polymers with CNTs as conductive fillers [40]. 


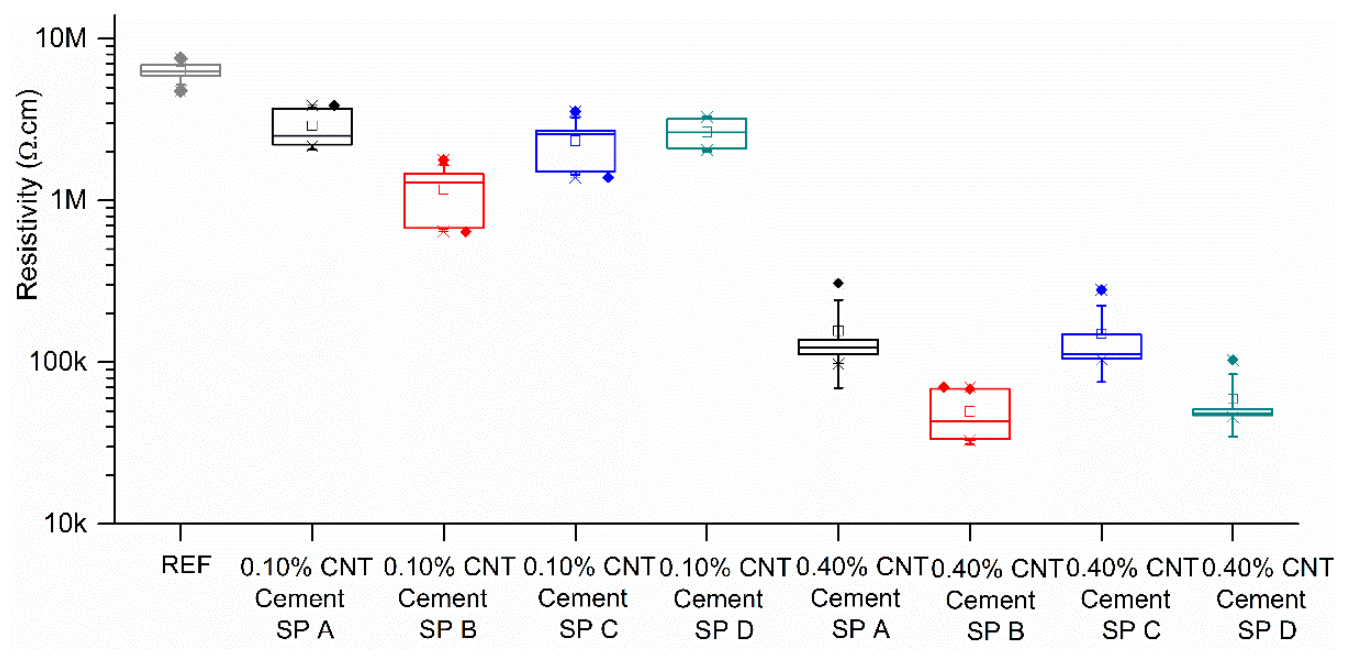

Figure 10. Electrical resistivity results for CNT-cement composites in partially dry condition (boxes presenting 25,50 , and $75 \%$ percentile, whiskers presenting one standard deviation, and solid symbols presenting outliers).

\section{General Discussion}

From observing the UV-Vis absorbance results, it was possible to identify that SPs B and D were the most efficient dispersing agents for CNT since they presented the highest absorbance value among the four products studied. FTIR spectra showed a key difference between these two SPs and the others, which was the lack of aliphatic groups in their structure. Additionally, $\zeta$-potential results showed that SP D was the only one capable of generating a stable colloid. FTIR results showed that SP D presented a main difference from the others SPs in the ether functional groups.

These structural differences between SP D and the others were already expected, since SP D is naphthalene-based, while the other three are ether polycarboxylate-based. The best behavior of SP D agrees with results found in Al-Rekabi et al. [41], who found that naphthalene-based superplasticizers worked better than ether polycarboxylate-based ones, despite being an older-generation plasticizer. Mendoza Reales [22] has also concluded that polycarboxylates ether are not the most adequate superplasticizer to be used as a dispersant agent and generate stable colloids.

Regarding the electrical properties of the studied CNT-cement composites, the lower dispersing efficiency of SPs A and C was found to be translated into longer electrical resistance stabilization times and higher electrical resistivity when compared with SPs B and D. The higher dispersing capability of SPs B and D, which was found to be associated with the lack of aliphatic groups in the SP structure, was confirmed to play an important role in generating CNT-cement composites with a low stable electrical resistivity.

\section{Conclusions}

CNT dispersions in aqueous solution with different superplasticizers as dispersing agents were investigated. Differences in performance were associated with the presence of aliphatic functional groups in their structure. It was concluded that the second-generation naphthalene-based superplasticizers are more efficient dispersing agents for CNTs than third-generation ether polycarboxylate-based superplasticizers.

Author Contributions: Conceptualization, C.F.T.S. and O.A.M.R.; Funding acquisition, R.D.T.F.; Investigation, P.d.A.C. and Y.G.d.S.M.; Supervision, O.A.M.R., E.d.M.R.F. and R.D.T.F.; Writingoriginal draft, P.d.A.C.; Writing-review \& editing, O.A.M.R. All authors have read and agreed to the published version of the manuscript. 
Funding: This study was financed in part by the Coordenação de Aperfeiçoamento de Pessoal de Nivel Superior-Brasil (CAPES)_Finance Code 001 and Conselho Nacional de Desenvolvimento Científico e Tecnológico-Brasil (CNPq).

Data Availability Statement: The data presented in this study are available within the article.

Acknowledgments: Part of the experimental tests was developed at Inorganic Chemistry Department and Raman Spectroscopy Multiuser Laboratory, both from Chemistry Institute of Federal University of Rio de Janeiro.

Conflicts of Interest: The funders had no role in the design of the study; in the collection, analyses, or interpretation of data; in the writing of the manuscript, or in the decision to publish the results.

\section{References}

1. Yu, M.F.; Lourie, O.; Dyer, M.J.; Moloni, K.; Kelly, T.F.; Ruoff, R.S. Strength and breaking mechanism of multiwalled carbon nanotubes under tensile load. Science 2000, 287, 637-640. [CrossRef] [PubMed]

2. Konsta-Gdoutos, M.S.; Metaxa, Z.S.; Shah, S.P. Highly dispersed carbon nanotube reinforced cement based materials. Cem. Concr. Res. 2010, 40, 1052-1059. [CrossRef]

3. Cwirzen, A.; Habermehl-Cwirzen, K.; Penttala, V. Surface decoration of carbon nanotubes and mechanical properties of cement/carbon nanotube composites. Adv. Cem. Res. 2008, 20, 65-73. [CrossRef]

4. Hunashyal, A.M.; Tippa, S.V.; Quadri, S.S.; Banapurmath, N.R. Experimental Investigation on Effect of Carbon Nanotubes and Carbon Fibres on the Behavior of Plain Cement Mortar Composite Round Bars under Direct Tension. ISRN Nanotechnol. 2011, 2011, 1-6. [CrossRef]

5. Hawreen, A.; Bogas, J.A.; Dias, A.P.S. On the mechanical and shrinkage behavior of cement mortars reinforced with carbon nanotubes. Constr. Build. Mater. 2018, 168, 459-470. [CrossRef]

6. Gillani, S.S.-H.; Khitab, A.; Ahmad, S.; Khushnood, R.A.; Ferro, G.A.; Saleem Kazmi, S.M.; Qureshi, L.A.; Restuccia, L. Improving the mechanical performance of cement composites by carbon nanotubes addition. Procedia Struct. Integr. 2017, 3, 11-17. [CrossRef]

7. Liew, K.M.; Kai, M.F.; Zhang, L.W. Carbon nanotube reinforced cementitious composites: An overview. Compos. Part A Appl. Sci. Manuf. 2016, 91, 301-323. [CrossRef]

8. Han, B.; Yu, X.; Ou, J. Multifunctional and Smart Carbon Nanotube Reinforced Cement-Based Materials. Nanotechnol. Civ. Infrastruct. 2011, 1, 1-47. [CrossRef]

9. Han, B.; Wang, Y.; Dong, S.; Zhang, L.; Ding, S. Smart concretes and structures: A review. J. Intell. Mater. Syst. Struct. 2015, 26, 1303-1345. [CrossRef]

10. Siad, H.; Lachemi, M.; Sahmaran, M.; Mesbah, H.A.; Anwar, K. Advanced engineered cementitious composites with combined self-sensing and self-healing functionalities. Constr. Build. Mater. 2018, 176, 313-322. [CrossRef]

11. Musso, S.; Tulliani, J.-M.; Ferro, G.; Tagliaferro, A. Influence of carbon nanotubes structure on the mechanical behavior of cement composites. Compos. Sci. Technol. 2009, 69, 1985-1990. [CrossRef]

12. Zhang, S.; Lu, F.; Zheng, L. Dispersion of multiwalled carbon nanotubes (MWCNTs) by ionic liquid-based Gemini pyrrolidinium surfactants in aqueous solution. Colloid Polym. Sci. 2011, 289, 1815-1819. [CrossRef]

13. Jiang, L.; Gao, L.; Sun, J. Production of aqueous colloidal dispersions of carbon nanotubes. J. Colloid Interface Sci. 2003, 260, 89-94. [CrossRef]

14. Mendoza, O.; Toledo, R. Nanotube-Cement Composites. In Carbon Nanomaterials Sourcebook: Nanoparticles, Nanocapsules, Nanofibers, Nanoporous Structures, and Nanocomposites; Sattler, K., Ed.; CRC Press: Boca Raton, FL, USA, 2016; Volume II, pp. 573-596.

15. Zou, B.; Jian, S.; Korayem, A.H.; Collins, F.; Wang, C.M. Effect of ultrasonication energy on engineering properties of carbon nanotube reinforced cement pastes. Carbon N. Y. 2014, 85, 212-220. [CrossRef]

16. Krause, B.; Mende, M.; Pötschke, P.; Petzold, G. Dispersability and particle size distribution of CNTs in an aqueous surfactant dispersion as a function of ultrasonic treatment time. Carbon N. Y. 2010, 48, 2746-2754. [CrossRef]

17. Nochaiya, T.; Chaipanich, A. Behavior of multi-walled carbon nanotubes on the porosity and microstructure of cement-based materials. Appl. Surf. Sci. 2011, 257, 1941-1945. [CrossRef]

18. Yazdanbakhsh, A.; Grasley, Z.; Tyson, B.; Abu Al-Rub, R.K. Distribution of Carbon Nanofibers and Nanotubes in Cementitious Composites. Transp. Res. Rec. J. Transp. Res. Board 2010, 2142, 89-95. [CrossRef]

19. Lu, L.; Ouyang, D.; Xu, W. Mechanical properties and durability of ultra high strength concrete incorporating multi-walled carbon nanotubes. Materials 2016, 9, 419. [CrossRef] [PubMed]

20. Szelag, M. Mechano-physical properties and microstructure of carbon nanotube reinforced cement paste after thermal load. Nanomaterials 2017, 7, 267. [CrossRef] [PubMed]

21. Gay, C.; Sanchez, F. Performance of Carbon Nanofiber-Cement Composites with a High-Range Water Reducer. Transp. Res. Rec. J. Transp. Res. Board 2010, 2142, 109-113. [CrossRef]

22. Mendoza, O.; Sierra, G.; Tobón, J.I. Influence of super plasticizer and $\mathrm{Ca}(\mathrm{OH})_{2}$ on the stability of functionalized multi-walled carbon nanotubes dispersions for cement composites applications. Constr. Build. Mater. 2013, 47, 771-778. [CrossRef] 
23. Mendoza Reales, O.A.; Ocampo, C.; Arias Jaramillo, Y.P.; Ochoa Botero, J.C.; Quintero, J.H.; Silva, E.C.C.M.; Toledo, R.D. Reinforcing Effect of Carbon Nanotubes/Surfactant Dispersions in Portland Cement Pastes. Adv. Civ. Eng. 2018, 2018, 1-9. [CrossRef]

24. Han, B.; Zhang, K.; Yu, X.; Kwon, E.; Ou, J. Fabrication of Piezoresistive CNT/CNF Cementitious Composites with Superplasticizer as Dispersant. J. Mater. Civ. Eng. 2012, 24, 658-665. [CrossRef]

25. Mendoza Reales, O.A.; Dias Toledo Filho, R. A review on the chemical, mechanical and microstructural characterization of carbon nanotubes-cement based composites. Constr. Build. Mater. 2017, 154, 697-710. [CrossRef]

26. Njuguna, J.; Vanli, O.A.; Liang, R. A Review of Spectral Methods for Dispersion Characterization of Carbon Nanotubes in Aqueous Suspensions. J. Spectrosc. 2015, 2015, 1-11. [CrossRef]

27. Hu, H.; Yu, A.; Kim, E.; Zhao, B.; Itkis, M.E.; Bekyarova, E.; Haddon, R.C. Influence of the zeta potential on the dispersability and purification of single-walled carbon nanotubes. J. Phys. Chem. B 2005, 109, 11520-11524. [CrossRef]

28. D’Alessandro, A.; Ubertini, F.; García-Macías, E.; Castro-Triguero, R.; Downey, A.; Laflamme, S.; Meoni, A.; Materazzi, A.L. Static and Dynamic Strain Monitoring of Reinforced Concrete Components through Embedded Carbon Nanotube Cement-Based Sensors. Shock Vib. 2017, 2017, 1-11. [CrossRef]

29. Janowska-Renkas, E. The effect of superplasticizers' chemical structure on their efficiency in cement pastes. Constr. Build. Mater. 2013, 38, 1204-1210. [CrossRef]

30. Osswald, S.; Havel, M.; Gogotsi, Y. Monitoring oxidation of multiwalled carbon nanotubes by Raman spectroscopy. J. Raman Spectrosc. 2007, 38, 728-736. [CrossRef]

31. Mendoza Reales, O.A.; Duda, P.; Dias Toledo Filho, R. Effect of a Carbon Nanotube/Surfactant Aqueous Dispersion on the Rheological and Mechanical Properties of Portland Cement Pastes. J. Mater. Civ. Eng. 2018, 30, 04018259. [CrossRef]

32. Mendoza, O.; Pearl, W.; Paiva, M.D.M.; Miranda, C.; Toledo Filho, R. Effect of a commercial dispersion of multi walled carbon nanotubes on the hydration of an oil well cementing paste. Front. Struct. Civ. Eng. 2016, 10, 147-179. [CrossRef]

33. Shih, J.; Chang, T.; Hsiao, T. Effect of nanosilica on characterization of Portland cement composite. Mater. Sci. Eng. A 2006, 424, 266-274. [CrossRef]

34. Srinivasan, S.; Barbhuiya, S.A.; Charan, D.; Pandey, S.P. Characterising cement-superplasticiser interaction using zeta potential measurements. Constr. Build. Mater. 2010, 24, 2517-2521. [CrossRef]

35. D'Alessandro, A.; Tiecco, M.; Meoni, A.; Ubertini, F. Improved strain sensing properties of cement-based sensors through enhanced carbon nanotube dispersion. Cem. Concr. Compos. 2021, 115, 103842. [CrossRef]

36. Cao, J.; Chung, D.D. Electric polarization and depolarization in cement-based materials, studied by apparent electrical resistance measurement. Cem. Concr. Res. 2004, 34, 481-485. [CrossRef]

37. Chiarello, M.; Zinno, R. Electrical conductivity of self-monitoring CFRC. Cem. Concr. Compos. 2005, 27, 463-469. [CrossRef]

38. Wansom, S.; Kidner, N.; Woo, L.; Mason, T. AC-impedance response of multi-walled carbon nanotube/cement composites. Cem. Concr. Compos. 2006, 28, 509-519. [CrossRef]

39. Jang, S.H.; Kawashima, S.; Yin, H. Influence of carbon nanotube clustering on mechanical and electrical properties of cement pastes. Materials 2016, 9, 220. [CrossRef] [PubMed]

40. Gong, S.; Zhu, Z.H.; Meguid, S.A. Carbon nanotube agglomeration effect on piezoresistivity of polymer nanocomposites. Polymer 2014, 55, 5488-5499. [CrossRef]

41. Al-rekabi, S.; Cundy, A.B.; Lampropoulos, A.; Savina, I.N. Experimental investigation of the effect of superplasticizer/surfactant aided aqueous dispersion of multi-walled Carbon nanotubes on workability and mechanical properties of cementitious composites. In Proceedings of the 25th Workshop and Colloquium, Regensburg, Germany, 2 March 2016. 